DOI:10.5433/1984-7939.2017v2n1p36

\title{
EDUCAÇÃO SUPERIOR DO SETOR PRIVADO NO MARANHÃO: EXPANSÃO E DESENVOLVIMENTO REGIONAL
}

\author{
Edgar Oliveira Santos ${ }^{1}$ \\ Edney Loiola ${ }^{2}$ \\ Sônia Oliveira Santos ${ }^{3}$
}

RESUMO: $O$ presente estudo analisa a expansão do ensino superior privado no Brasil e sua contribuição para o desenvolvimento regional; para tanto, utiliza-se da experiência vivenciada na região sul do estado do Maranhão principalmente a partir da primeira década do século XXI focalizando possiveis influências desse ensino privado no desenvolvimento. Assim, propõe como objetivo esclarecer elementos tácitos do propósito dessa expansão no segmento privado. Os fundamentos teóricos metodológicos apoiam-se nos comentários críticos de autores como Gaudêncio Frigotto observando uma educação para os ditames de uma expansão do ensino superior de bases capitalistas, ao passo que José Eli da Veiga, Celso Furtado e Pedro Demo observam elementos da estrutura conceitual do estudo do desenvolvimento destacando educação, cultura e qualidade de vida como essenciais na consecução do progresso regional. Os resultados são consubstanciados com dados censitários do Instituto Nacional de Estudos e Pesquisas Educacionais Anísio Teixeira (INEP) e do Instituto Brasileiro de Geografia e Estatística (IBGE), que permitem detectar indícios, de uma expansão orientada na perspectiva do fortalecimento do poder hegemônico, estruturado sob a forma de grandes multinacionais do campo educacional, operando a partir da crise e falência das pequenas e médias instituições de ensino superior do segmento privado da educação, exemplificadas na realidade sul-maranhense.

Palavras chaves: Acesso ao ensino superior. Ensino privado. Desenvolvimento regional.

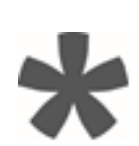

1 Professor da Universidade Estadual da Região Tocantina - UEMASUL, Mestre em Educação pelo Instituto Latinoamericano e Caribenho, Mestre em Planejamento do Desenvolvimento - NAEA/UFPA, doutorando do Programa de Desenvolvimento Regional da UNISC. E-mail: ehonsda@gmail.com

2 Professor da Universidade Estadual da Região Tocantina do Maranhão - UEMASUL, Doutor em Desenvolvimento Socioambiental (NAEA/UFPA). E-mail: edneyloiola@uol.com.br

3 Professora da Universidade Cruzeiro do Sul (UNICSUL). Mestre em Políticas Sociais. E-mail: sonia7_oliveira@hotmail.com 
Santos, E.O.; Loiola, E.; Santos, S.O

\title{
HIGHER EDUCATION OF THE PRIVATE SECTOR IN MARANHÃO: EXPANSION AND REGIONAL DEVELOPMENT
}

\begin{abstract}
The present study analyzes the expansion of private higher education in Brazil and its contribution to regional development, using both the experience lived in the southern region of the state of Maranhão mainly from the first decade of the twenty-first century focusing on possible influences of private education in such a development. Thus, it aims to clarify the tacit elements of the purpose of this expansion in the private segment. The theoretical methodological foundations are based on the critical comments of authors such as Gaudêncio Frigotto observing an education for the dictates of an expansion of higher education of capitalist bases, while José Eli da Veiga, Celso Furtado and Pedro Demo observe elements of the conceptual structure of Development, highlighting education, culture and quality of life as essential in achieving regional progress. The results are consubstantiated with census data from the National Institute of Educational Studies and Research Anisio Teixeira (INEP) and the Brazilian Institute of Geography and Statistics (IBGE), which allow us to detect evidence of an expansion oriented towards the strengthening of hegemonic power, structured under the Form of large multinationals of the educational field, operating from the crisis and bankruptcy of small and medium institutions of higher education of the private segment of education, exemplified in the reality of South America.
\end{abstract}

Keywords: Access to higher education. Private education. Regional development.

\section{EDUCACIÓN SUPERIOR DEL SECTOR PRIVADO EN EL MARANHÃO: EXPANSIÓN Y DESARROLLO REGIONAL}

RESUMEN: El presente estudio analiza la expansión de la enseñanza superior privada en Brasil y su contribución al desarrollo regional; por lo tanto, se utiliza de la experiencia vivenciada en la región sur del estado de Maranhão, principalmente a partir de la primera década del siglo XXI, enfocando posibles influencias de esa enseñanza privada en el desarrollo. Así se propone como objetivo aclarar elementos tácitos del propósito de esa expansión en el segmento privado. Los fundamentos teórico-metodológicos se apoyan en los comentarios críticos de autores como Gaudencio Frigotto observando una educación para los dictámenes de una expansión de la enseñanza superior de bases capitalistas, mientras que José Eli da Veiga, Celso Furtado y Pedro Demo observan elementos de la estructura conceptual del estudio del desarrollo destacando educación, cultura y calidad de vida como esenciales en la consecución del progreso regional. Los resultados son consubstanciados con datos censales del Instituto Nacional de Estudios e Investigaciones Educativas Anísio Teixeira (INEP) y del Instituto Brasileño de Geografia y Estadística (IBGE), que permiten detectar indicios, de una expansión orientada en la perspectiva del fortalecimiento del poder hegemónico, de las grandes multinacionales del campo educativo, operando a partir de la crisis y la quiebra de las pequeñas y medianas instituciones de enseñanza superior del segmento privado de la educación, ejemplificadas en la realidad del sur de Maranhão.

Palabras claves: Acceso a la enseñanza superior. Enseñanza privada. Desarrollo Regional 


\section{Introdução}

A educação no processo de desenvolvimento tem favorecido a construção de inúmeras temáticas nas discussões econômicas e sociais. A relação educação e desenvolvimento tornou-se uma expressiva proposição nos distintos planos governamentais sobretudo os que se destinam ao desenvolvimento regional.

Construir essa relação respeitando a diversidade regional brasileira é buscar uma melhor aproximação com essa realidade, é sobretudo alinhar a educação com os valores culturais dessa sociedade brasileira que se pretende desenvolver, com a consequente melhoria das condições de vida da população. Nessa concepção, o desenvolvimento é econômico entendendo que, as formas de produção orientadas pela educação conduzirão seus atores a um nivel de negociação compatível com suas necessidades vitais.

A estrutura organizada para desenvolver o Brasil na década de 1950 não transmitiu essa ideia, uma vez que, o pensamento convergia basicamente para o desenvolvimento industrial promovendo planejamentos empresariais do setor privado elevando a produção de bens de capital e bens de consumo duráveis, com taxas anuais de aproximadamente 25\%. Esse desenvolvimento foi marcado por um período de grande geração de emprego, crescimento e ampliação da classe proletária e fortalecimento do mercado de consumo. Contudo, o Estado brasileiro estava a serviço do capital estrangeiro, com o domínio de grandes empresas internacionais nessa economia nacional (FAUSTO, 1995).

A visão conceitual desse crescimento econômico, naquela época, era de desenvolvimento, mas para Veiga (2005) não se deve esquecer que no crescimento a mudança é quantitativa e no desenvolvimento é qualitativa, com essa posição o autor ainda afirma que ambos estão intimamente ligados, porém não são a mesma coisa, observa-se que os dois são tão unidos sendo quase impossivel separá-los.

Se uma parte da população está desempregada e ocorre uma determinada expansão da atividade econômica, o nível de desemprego é reduzido, assim, neste caso, houve melhoria da qualidade de vida com o 
crescimento da economia e essa qualidade de vida não é um quantitativo como o PIB, mas o que é qualidade de vida? Para a Organização Mundial de Saúde qualidade de vida é: "a percepção do indivíduo de sua posição na vida no contexto da cultura e sistema de valores, nos quais ele vive e em relação aos seus objetivos, expectativas, padrões e preocupações" (FLECK, 2000, p. 179). Dessa forma, diferentemente de outros instrumentos utilizados para avaliação de qualidade de vida, o meio empregado para medir esse item do desenvolvimento humano deveria basear-se nos pressupostos de que qualidade de vida é um construto subjetivo (percepção do indivíduo em questão), multidimensional e composto por dimensões positivas.

Os níveis de qualidade de vida, analisando por essa ótica, apresentamse de formas diversificadas. Segundo as variáveis que podem ser consideradas em função das origens da população e as circunstâncias que em um momento específico, e naquele espaço são determinantes, para as escolhas diante das necessidades subjacentes, mas esse esforço conceitual orienta a tentativa de harmonizar crescimento e desenvolvimento diante das situações determinadas em consideração ao tempo, espaço, consequências e circunstâncias.

O Índice de Desenvolvimento Humano - IDH classifica os lugares principalmente com indicadores de saúde, renda e educação e tem sido utilizado desde 1993, contudo, não consegue acompanhar e, consequentemente, medir determinados atributos aliados aos indivíduos, dentro dos novos processos da ocupação espacial como: aglomeração urbana, metropolização incluindo as longas distâncias para o trabalho, elevação do índice de violência, poluição, distribuição de renda, entre outros.

O desenvolvimento regional condicionado pela educação como objeto de estudo deste trabalho segue a linha conceitual do Programa das Nações Unidas para o Desenvolvimento, em que o desenvolvimento tem a ver, primeiro e acima de tudo, com a possibilidade de as pessoas viverem o tipo de vida que escolheram, e com a provisão dos instrumentos e das oportunidades para fazerem as suas escolhas (VEIGA, 2005), contudo, torna-se necessário esclarecer o papel da educação em sua inserção desenvolvimentista. 
Analisando a história da educação no Brasil, a partir dessa concepção é possível entender sobre a inércia de criação de um sistema nacional de educação, que permitisse uma conexão capaz de induzir o desenvolvimento, pois somente no período compreendido entre o final da década de 1950 e início dos anos 60 o movimento educacional em busca de novas reformas conseguiu implantar movimentos de cultura popular como, erradicação do analfabetismo e de educação popular, que mesmo não sendo ações diretas e intencionais de desenvolvimento, contribuiu, de certo modo, para despertar interesses, pela melhoria da qualidade de vida tendo como base a educação (FRIGOTTO, 2000).

A partir do esforço conceitual de crescimento econômico e desenvolvimento (VEIGA, 2005) aliado aos registros históricos de manifestações educacionais, no início da década de 1960, o presente artigo pretende analisar a expansão do ensino superior privado e sua contribuição para o desenvolvimento regional, para tanto utilizar-se-á como fulcro a experiência vivenciada na região sul do estado do Maranhão, com a expansão do ensino superior privado. As abordagens estão distribuídas em cinco seções: introdução; discussões teóricas sobre educação superior; a expansão desse ensino no Brasil; o ensino superior na região sul maranhense; e as considerações finais.

\section{Ensino Superior e Desenvolvimento: aportes teóricos}

A educação superior sob a égide da Lei 9394/96, das Diretrizes e Bases da Educação - LDB apresenta um destacado compartimento estrutural permitindo que a universidade atual possa desempenhar suas funções essenciais, de formar profissionais, promover educação em nivel avançado, realizar estudos, pesquisas e investigação científica, voltados para o desenvolvimento e exercer a função de responsabilidade social. Nessa perspectiva, a instituição de ensino superior adquire condições de buscar alternativas, para os distintos desafios da sociedade brasileira, a qual interage com uma realidade marcada por profundas desigualdades sociais (BRASIL, 1996). 
A abordagem no presente estudo analisa fatos recentes voltados para a expansão desse ensino, abstendo-se de um historicismo da educação superior. No entanto não é justo prescindir de ressaltar que, a educação brasileira apresenta-se com vestígios de um projeto da burguesia, que projeta profissionais com foco na produtividade, por conseguinte os novos conhecimentos, as novas tecnologias determinam também, um novo padrão de acumulação de capital, cuja grande maioria dos governos periféricos se ajusta à reengenharia e à reestruturação produtiva, flexibilizam, desregulamentam acreditando num mercado autorregulado (FRIGOTTO, 1999).

Essa diligente derivação para o reducionismo econômico e sociológico é provocado pela insuficiência de uma teoria geral do homem, uma antropologia filosófica, em consequência disso não se sabe ao certo a razão pela qual, neste ou naquele momento de sua história uma sociedade favorece a criação de técnicas e não de valores substantivos, menos conhecidos ainda são os determinantes que orientam a criatividade de valores substantivos para o plano politico, religioso ou do saber (VEIGA, 2005; FURTADO, 2008).

Com base nos questionamentos propugnados no parágrafo anterior, percebe-se que a relação mais forte entre educação e desenvolvimento passa pela questão da qualidade política, ou seja, pela competência humana de se fazer sujeito capaz de escrever sua própria história, pois nesse caso a melhor luta que a educação pode travar é contra a pobreza política, no sentido de consolidar a cidadania crítica e prática voltada para projetos alternativos de desenvolvimento. Nessa ótica, a ignorância aparece como maior problema social a ser enfrentado, porque esta bloqueia a capacidade de cada um encontrar soluções (DEMO, 1999).

Complementando as inserções acima verifica-se que os elementos conceituais do desenvolvimento se estabelecem como um dos maiores desafios teóricos do século XXI e diante dessa complexidade caracterizada pela abertura a múltiplos conceitos, as diferentes concepções existentes sobre o desenvolvimento não devem ser consideradas excludentes, mas sim interligadas e complementares, desse modo é possivel pensar um modelo baseado na descoberta de potencialidades, para a construção de uma 
sociedade mais justa e igualitária, permitindo erradicar a pobreza e a marginalização e reduzir as desigualdades sociais e regionais (CHAVES, 2014).

A educação superior apresenta-se como um nivel destacado da educação, principalmente por viabilizar um estudo crítico da realidade e por isso tem papel importante na promoção do desenvolvimento. Nessa perspectiva aliam-se as orientações teóricas considerando que o desenvolvimento pode ser visto como um processo de ampliação das liberdades reais de que uma pessoa desfruta, sendo assim, o realce nas liberdades humanas se opõe às perspectivas mais restritas de desenvolvimento, na qual o identificam com o crescimento do produto nacional, com o aumento das receitas, com a industrialização e com a expansão tecnológica (SEN, 1999).

Esse nivel educacional apesar do destaque citado acima continua sendo instituição social que mediante suas práticas no âmbito do conhecimento, articula determinados interesses e desarticula outros, pois isso significa subordinar a função social da educação para atender às demandas do sistema capitalista, em que no contexto neoliberal a educação apresenta-se com a missão de formar o trabalhador para o processo produtivo que, nesse caso, a educação nos diferentes grupos sociais de trabalhadores ocorre visando construir habilidade técnica, social e ideologicamente para o trabalho (FRIGOTTO, 1999).

Como não há pretensão de um aprofundamento nas colocações teóricas atinentes a desenvolvimento e educação, mas de estabelecer uma devida conexão com a expansão do ensino privado no contexto nacional/regional, é mister inserir neste parágrafo pontos de vista de Cunha (2007) quando questiona a imagem do desenvolvimento da educação brasileira como um processo generalizado e contínuo de privatização, pois para ele a privatização é um complicado processo, que incide sobre múltiplas respostas, considerando que, a segmentação dos sistemas educacionais não obedece a um trajeto retilíneo, sendo determinada por forças como estado e o mercado, que ora incentivam o crescimento do setor público, ora do setor privado, ora de ambos (CUNHA, 2007, p. 809-811). 


\section{Ensino Superior No Brasil: uma expansão às avessas}

A educação superior no Brasil se integrou num processo de expansão, tendo como base a década de 1990 fundamentado pela Constituição Federal de 1988, que através dos seus artigos 205 a 217 permite o entendimento de viabilidade da ampliação do sistema educacional, principalmente o de nível superior. A criação da Lei 9394/96, de Diretrizes e Bases da Educação Nacional, LDB, permitiu maior incremento desse nível da educação, pois de acordo com dados do Instituto Nacional de Estudos e Pesquisas Educacionais Anísio Teixeira - INEP houve um crescimento expressivo da educação no país no período de 1996 até 2004, com destaque para o Nordeste e em especial no Maranhão e Piauí, como mostra o quadro a seguir.

Quadro 1 - Expansão do número de cursos superiores - Nordeste/NE $1996-2004$

\begin{tabular}{|c|c|c|c|c|c|c|c|c|c|c|}
\hline \multicolumn{2}{|c|}{ Ano } & 1996 & 1997 & 1998 & 1999 & 2000 & 2001 & 2002 & 2003 & 2004 \\
\hline \multicolumn{2}{|c|}{ Total/NE } & 1.031 & 934 & 1.134 & 1.467 & 1.662 & 1.978 & 2.514 & 2.927 & 3.318 \\
\hline \multirow{9}{*}{$\begin{array}{l}\text { UF } \\
\text { do } \\
\mathrm{NE}\end{array}$} & $\mathrm{AL}$ & 60 & 57 & 72 & 88 & 91 & 101 & 123 & 143 & 153 \\
\hline & BA & 183 & 172 & 211 & 304 & 348 & 410 & 520 & 599 & 729 \\
\hline & $\mathrm{CE}$ & 136 & 114 & 129 & 144 & 161 & 185 & 236 & 263 & 311 \\
\hline & MA & 97 & 79 & 90 & 103 & 115 & 155 & 309 & 410 & 575 \\
\hline & $\mathrm{PB}$ & 108 & 104 & 108 & 122 & 130 & 137 & 150 & 165 & 186 \\
\hline & $\mathrm{PE}$ & 205 & 177 & 185 & 222 & 234 & 277 & 325 & 363 & 398 \\
\hline & PI & 84 & 80 & 172 & 208 & 297 & 409 & 494 & 588 & 569 \\
\hline & RN & 90 & 103 & 111 & 149 & 152 & 166 & 213 & 255 & 248 \\
\hline & $\mathrm{SE}$ & 68 & 48 & 56 & 127 & 134 & 138 & 144 & 141 & 149 \\
\hline
\end{tabular}

Fonte: Adaptado de INEP (2009).

O crescimento proporcional do número de cursos de 1996 a 2004, no quadro 1 demonstra que os estados do Maranhão e Piauí receberam um incremento significativo em relação aos demais estados do Nordeste. Essa realidade quantitativa induz a suposição de que uma grande carência de oferta de cursos superiores nos dois estados propiciou uma maior motivação para a referida expansão e para ilustrar informação sobre essa reduzida existência de cursos em anos anteriores consta no Censo da Educação Superior (1991), que 
o Maranhão, quarto maior do Nordeste em população registrava 61 cursos superiores enquanto estados como Paraíba e Rio Grande do Norte com 95 e 77 cursos, respectivamente, mesmo com contingentes populacionais bem menores (INEP, 2009, p. 33).

Os comentários em torno dos dados numéricos acima estabelecem uma relação com o estudo do crescimento do ensino superior privado no sul do Maranhão, que incorporou oficialmente esse segmento a partir de 2001 e em função disso é interessante analisar os dois segmentos (público e privado) com base no quadro a seguir.

Quadro 2 - Instituições de ensino superior - Maranhão 2001/2008

\begin{tabular}{|c|c|c|c|}
\hline ANO & PÚBLICO & PRIVADO & TOTAL \\
\hline 2001 & 03 & 08 & 11 \\
\hline 2002 & 03 & 11 & 14 \\
\hline 2003 & 03 & 14 & 17 \\
\hline 2004 & 03 & 18 & 21 \\
\hline 2005 & 03 & 22 & 25 \\
\hline 2006 & 03 & 22 & 25 \\
\hline 2007 & 03 & 25 & 28 \\
\hline 2008 & 04 & 25 & 29 \\
\hline
\end{tabular}

Fonte: Adaptado de INEP (2011).

O Maranhão conforme Resumo Técnico (INEP, 2009, p. 31) possuía 3 IES no setor público em 1991, no ano de 2001 incorpora mais 08 do setor privado e como se observa no quadro 2, os números cresceram acentuadamente a cada ano nesse setor enquanto no âmbito público surge apenas mais uma unidade em 2008. Esses dados vistos dessa forma suscitam, logicamente, comentários críticos nos próximos parágrafos, sobre a compatibilidade da oferta e demanda, considerando a ótica socioeconômica haja vista, que o esforço maior está centrado na iniciativa privada.

É possivel entender que essa expansão do ensino superior implantada no final do século $\mathrm{XX}$ de forma rápida e liderada pela iniciativa privada apresentava-se com investimentos priorizando a estrutura física, que para educação parecia algo efêmero, pois naquela época as exigências sobre qualificação do corpo docente para esse segmento não eram rigorosas, por 
outro lado, no Programa de Apoio à Reestruturação e Expansão das Universidades Federais, criado em 2007, constava a criação de condições para a ampliação do acesso e permanência na educação superior, no nível de graduação.

No entendimento de Sguissardi (2006), a reduzida expansão do setor público e o grande crescimento do setor privado demonstram inicialmente uma acentuada limitação do financiamento para o ensino superior público e no entanto criou-se facilidades de implantação de IES privadas, com finalidades de lucro. Buscando evidenciar essa relação (público/privado) no âmbito nacional, o quadro a seguir apresenta-se de forma conjugada para melhor análise, com uma evolução das IES, cursos e matrículas na primeira década deste século XXI.

Quadro 3 - Número de IES, cursos e matrículas - público/privado Brasil $2000 / 2010$

\begin{tabular}{|c|c|c|c|c|c|c|c|c|c|}
\hline & \multicolumn{3}{|c|}{ Instituições } & \multicolumn{3}{c|}{ Cursos } & \multicolumn{3}{c|}{ Matrículas } \\
\hline Ano & Total & Pública & Privada & Total & Pública & Privada & Total & Pública & Privada \\
\hline 2000 & 1.180 & 176 & 1.004 & 10.585 & 4.021 & 6.564 & 2.694 .245 & 887.026 & 1.807 .219 \\
\hline 2001 & 1.391 & 183 & 1.208 & 12.155 & 4.401 & 7.754 & 3.030 .754 & 939.225 & 2.091 .529 \\
\hline 2002 & 1.637 & 195 & 1.442 & 14.399 & 5.252 & 9.147 & 3.479 .913 & 1.051 .655 & 2.428 .258 \\
\hline 2003 & $1 ! 859$ & 207 & 1.652 & 16.453 & 5.662 & 10.791 & 3.887 .771 & 1.137 .119 & 2.750 .652 \\
\hline 2004 & 2.013 & 224 & 1.789 & 18.644 & 6.262 & 12.382 & 4.163 .733 & 1.178 .328 & 2.985 .405 \\
\hline 2005 & 2.165 & 231 & 1.934 & 20.407 & 6.191 & 14.216 & 4.453 .156 & 1.192 .189 & 3.260 .967 \\
\hline 2006 & 2.270 & 248 & 2.022 & 22.101 & 6.549 & 15.552 & 4.676 .646 & 1.209 .304 & 3.467 .342 \\
\hline 2007 & 2.281 & 249 & 2.032 & 23.488 & 6.596 & 16.892 & 4.880 .381 & 1.240 .968 & 3.639 .413 \\
\hline 2008 & 2.252 & 236 & 2.016 & 24.719 & 6.772 & 17.947 & 5.080 .056 & 1.273 .965 & 3.806 .091 \\
\hline 2009 & 2314 & 245 & 2069 & 28671 & 8628 & 20.043 & 5.115 .896 & 1.351 .168 & 3.764 .728 \\
\hline 2010 & 2.377 & 278 & 2.099 & 29.507 & 9.245 & 20.262 & 6.379 .299 & 1.643 .298 & 4.736 .001 \\
\hline
\end{tabular}

Fonte: Adaptado de INEP (2009, 2010, 2011).

O grande número de matrículas na IES privada, no quadro anterior é impressionante quando se observa que, no ano 2000, o ensino superior privado teve 1.807.219 matrículas, em 2010 atingiu 4.736.001 de matrículas. É interessante ressaltar que basicamente, nesse periodo, verificou-se através de dados do Censo/INEP (2001/2010), um registro crescente de vagas ociosas em 
relação ao número de vagas ofertadas. Assim destacam-se os seguintes percentuais de vagas: no ano de 2001, 26,39\% ficaram ociosas; em 2002 passam para $32,03 \%$ e segue de forma crescente atingindo 49,55\% em 2008; $52,2 \%$ em 2009 e $49 \%$ em 2010, sendo que a maioria pertencente ao setor privado (INEP, 2011). Nessa perspectiva, observa-se que houve um grande estímulo para investimento por parte da iniciativa privada, como se verifica pelos números de IES, cursos e, consequentemente, de matrículas. Esse excesso pode ter dificultado o amadurecimento acadêmico, necessário à formação de padrões mínimos de qualidade. (MOEHLECKE; CATANI, 2006).

Entre as causas que contribuem para a ociosidade estão as dificuldades financeiras para pagar mensalidades como também a diversificação e qualidade do sistema (turno, área e modalidade - presencial e a distância, bacharelados, tecnológicos e licenciaturas), que estão aliadas a empecilhos de permanência, como dificuldade de transporte, falta de moradia estudantil, recursos para a alimentação, assistência médica, bolsas de estudo e pesquisa, etc. Esses aspectos apresentam ainda uma relação com as condições socioeconômicas da região onde foram implantadas as instituições (AMBIEL, 2015).

\section{Ensino Superior no Sul Maranhense}

Com o intuito de estabelecer uma origem do ensino superior no Maranhão estruturam-se a partir deste parágrafo alguns registros iniciais desse ensino, o qual assinala desde o final do século XVIII e por quase todo o XIX uma movimentação das famílias mais abastadas encaminhando seus filhos para estudar nas universidades do velho mundo, notadamente em Portugal. Isso contribuiu para que inicialmente não fosse sentida a necessidade de cursos superiores no Maranhão (FERRO, 2005, p. 178-181).

Dessa forma, um período de grande esplendor cultural passou sem contribuir para o desenvolvimento do ensino superior e, somente com o advento da República, em 1889, surgem as escolas desse gênero, no início, particulares, sem vinculação religiosa, a primeira dessas escolas foi a Faculdade de Direito de São Luís em 28 de abril de 1918 em seguida surgem outras de orientação religiosa e a Fundação Universidade do Maranhão (FUM), 
que passou em seguida para a denominação de Universidade Federal do Maranhão - UFMA (FERRO, 2005).

Essa representação simbólica dos primórdios do ensino superior no estado do Maranhão, com dinâmicas espaciais centradas em São Luís, a capital, difere dos registros encontrados sobre as origens do ensino superior na região sulmaranhense, pois o marco inicial espacial ocorre no município de Imperatriz, na segunda metade do século XX, quando esse nível da educação, nessa região, originou-se com a criação da Fundação de Ensino Superior de Imperatriz (FEI) em 1973. É importante esclarecer, que depois da capital onde teve início ensino superior, a segunda realidade oficial do ensino superior ocorreu nessa região do sul do estado, representado por esse município referenciado acima (ENCICLOPÉDIA DE IMPERATRIZ, 2003).

Em 1994, essa instituição recebeu denominação de Centro de Estudos Superiores de Imperatriz - CESI e durante seus 21 anos (1973 a 1994) e através de sua abrangência regional formou 1.073 profissionais em licenciatura curta e 139 em licenciatura plena. Nota-se que além da implantação do CESI/UEMA surgiu na mesma década de 1970 o projeto de interiorização da Universidade Federal do Maranhão - UFMA implantando assim, os cursos de Direito, Pedagogia e Ciências Contábeis nesse municipio (ANDRADE, 2006, p. 55-78).

O sul desse estado representado por Imperatriz limita-se com os estados do Pará e Tocantins e justifica sua ascensão educacional tardia pela inexistência de comunicação terrestre para veículos até o final da década de 1950 e somente a partir da construção da rodovia Belém Brasília - BR 010, esse município inicia um rápido processo de transformação, pois seu crescimento econômico é evidenciado a partir da década de 1960, como consta nos dados do Instituto Brasileiro de Geografia e Estatística - IBGE, no quadro a seguir referenciado pelo crescimento populacional (NEGREIROS, 1996). 
Quadro 4 - Evolução da população de Imperatriz 1950 - 2000

\begin{tabular}{|c|c|c|c|c|c|c|}
\hline ANOS & TOTAL & RURAL & URBANA & $\begin{array}{c}\text { RURAL } \\
\%\end{array}$ & $\begin{array}{c}\text { URBANA } \\
\%\end{array}$ & $\begin{array}{c}\text { TX/CRESCIMENTO } \\
\text { ANUAL }\end{array}$ \\
\hline 1950 & 14.064 & 12.434 & 1.630 & 88,41 & 11,59 & \\
\hline 1960 & 39.169 & 30.182 & 8.987 & 77,06 & 22,94 & $1950-1960=10,79 \%$ \\
\hline 1970 & 80.722 & 46.013 & 34.709 & 57,00 & 43,00 & $1960-1970=7,50 \%$ \\
\hline 1980 & 220.469 & 108.651 & 111.818 & 49,28 & 50,72 & $1970-1980=10,57 \%$ \\
\hline 1991 & 276.440 & 10.674 & 209.970 & 24,05 & 75,95 & $1980-1991=2,08 \%$ \\
\hline 2000 & 230.566 & 11.893 & 218.555 & 5,16 & 94,84 & $1996-2000=0,5 \%$ \\
\hline
\end{tabular}

Fonte: Elaborado pelos autores, dados dos Censos Demográficos do IBGE, 1950, 1960,1970, 1980, 1991 e 2000.

Observando o quadro 4, verifica-se o surgimento de uma dinâmica populacional em torno desse municipio principalmente no período de 1960 a 1980, contudo o ensino superior foi iniciado em 1973, pois é oportuno frisar que nessa época a universidade no Brasil já havia construído grandes registros de participação no cenário nacional, no entanto, o municipio de Imperatriz, no período de 1973 até 2000 representava esse ensino através de duas unidades, da UFMA e UEMA, com uma oferta limitada de cursos para atender toda a região sul composta por 49 municípios e ainda outros vizinhos do sul do estado do Pará e norte do Tocantins.

O sul do Maranhão referenciado pelo seu município mais importante demonstrou um cenário socioeconômico no ano de 2000, conforme pesquisa realizada pelo Escritório Técnico de Estudos Econômicos do Nordeste ETENE/BNB com os seguintes dados: $89 \%$ da população recebia até 2 salários mínimos e esse contingente respondia por $47 \%$ da renda desse município, enquanto a pequena parcela da população (11\%) se apropriava de 53\% da renda de Imperatriz. Essa realidade econômica está associada à vocação comercial desse município segundo essas pesquisas e no entanto, como mostra o quadro 5 a seguir, o fluxo de investimentos na criação de instituições e cursos não demonstram que houve um aprimorado planejamento sobre condições econômicas da demanda potencial, para ensino superior privado desse municipio (ETENE, 2002; SANTOS, 2008). 
Quadro 5 - Instituições de ensino superior e cursos - Imperatriz $1999 / 2013$

\begin{tabular}{|c|c|c|c|}
\hline IES & \multicolumn{2}{|c|}{ CURSOS } & \multirow{2}{*}{ TIPO } \\
\cline { 2 - 3 } & Ativos & Inativos & \\
\hline COC - Centro de Educação Internacional & 13 & 03 & Ead \\
\hline FACIMP - Faculdade de Imperatriz & 10 & 06 & Presencial \\
\hline FAMA - Faculdade Atenas Maranhense & 01 & 05 & Presencial \\
\hline FEST- Faculdade de Educação Santa Teresinha & 06 & 00 & Presencial \\
\hline FTC - Faculdade de Tecnologia e Ciência & 07 & 00 & Ead \\
\hline IESMA- Instituto de Ensino Superior do Maranhão & 07 & 03 & Presencial \\
\hline IFMA - Instituto Federal de Educação, Ciência e & 03 & 00 & Presencial \\
Tecnologia do Maranhão & & & \\
\hline UAM - Universidade Anhembi Morumbi & 04 & 00 & Ead \\
\hline Universidade Estadual do Maranhão & 13 & 00 & 2 tipos \\
\hline Universidade Federal do Maranhão & 05 & 00 & Presencial \\
\hline Universidade Federal de Santa Catarina & 14 & 00 & Ead \\
\hline UMESP- Universidade Metodista de São Paulo & 15 & 03 & Ead \\
\hline UNIGRAN - Centro Universitário da Grande & 10 & 02 & Ead \\
\hline Dourados & & & \\
\hline UNINTER - Centro Universitário Internacional & 17 & 00 & Ead \\
\hline UNIP - Universidade Paulista & 03 & 00 & Ead \\
\hline UNISUL - Universidade do Sul de Santa Catarina & 32 & 00 & Ead \\
\hline TOTAL & 160 & 22 & \\
\hline
\end{tabular}

Fonte: Elaboração dos autores, extraído Sistema E-mec/MEC, em 25/03/2013.

Admitindo que na Região Sul do Maranhão até 1999 existiam duas instituições de ensino, esse quadro 5 expressa um provável resultado da permissividade da expansão desse ensino, que aliado a um processo de crescimento econômico apresentado pela dinâmica populacional no quadro 4, condicionou investimentos no setor privado da educação superior, e apesar do período 1999/2013 os registros significativos de expansão aparecem a partir de 2001 com o advento das IES privadas, principalmente nesse municipio, pois é notório pelos indicadores acima incluindo não somente os números, mas também as distintas IES e modalidade dos cursos, que o intuito de expandir receitas ficou mais evidenciado do que os aspectos intrínsecos da educação superior.

No ponto de vista de Sampaio (2000), apesar do setor privado ter atingido números que lhes conferem uma posição destacada no sistema nacional de ensino, em 2000 não sinalizava até aquele ano indícios de 
mudanças significativas na sociedade brasileira, no entanto observa-se que os números do setor privado no início do século XXI indicaram desaceleração do crescimento das matrículas, com taxas decrescentes de crescimento, nota-se que no ano de 2008, a relação candidato-vaga nesse setor foi de 0,5 e no setor público foi de 0,9 ou seja, havia mais vagas no sistema do que candidatos (INEP, 2010).

\section{Prolegômenos de uma imponderável expansão educacional}

A expansão do ensino superior traduzida num olhar quantitativo, imposta à educação brasileira, difere da visão de Saviani (2010), pois este afirma que é preciso reverter a tendência de grande crescimento do número de vagas nas IES privadas fazendo com que, a prioridade passe das instituições privadas para as públicas, estas dotadas de bom nivel de qualificação. Para esse autor, a expansão das vagas nas universidades públicas, sob uma ótica da qualidade provocará uma ampliação da produção científica, que é essencial para o processo de desenvolvimento do país, uma vez que o foco na quantidade ameaça as possibilidades de desenvolvimento científico e tecnológico.

O desenvolvimento regional, influenciado pela educação superior, tem espaço através da extensão universitária, mas as configurações atuais das IES privadas fruto dessa expansão, geralmente priorizam o ensino em detrimento da pesquisa e extensão, que funcionam como atributos das públicas. Nesse caso, como demonstram os percentuais totalizadores de Instituições de Ensino Superior no Brasil - 12\% refere-se às públicas e $88 \%$ às instituições privadas, a inserção social da universidade apresenta-se deficitária, considerando que o planejamento do Governo Federal não priorizou o desenvolvimento, mas uma educação a serviço do crescimento econômico, coerente com as diretrizes neoliberais (INEP, 2011).

As mudanças ajustadas ao grande poder global, focadas na excelência produtiva, valorizam o quantitativo inclusive na educação, e os governos periféricos se ajustam à reengenharia e à reestruturação produtiva, flexibilizam, desregulamentam e apostam, cada vez mais, no mercado autorregulado, haja vista evidentemente, que a educação no Brasil apresenta 
resquícios de um projeto da burguesia, que forma profissionais, com foco na produtividade (FRIGOTTO, 2000).

Nessa perspectiva expansionista, o governo envolveu o segmento privado, pois era preciso alcançar um patamar de país emergente em um curto espaço de tempo e somente o investimento público para educação não seria suficiente, em consequência disso, as transformações ocorridas com essa ampliação, também mobilizou o governo a criar um programa de crescimento da oferta de vagas no ensino superior público, sem apresentar um estudo sobre o número de profissionais docentes disponiveis no mercado, bem como um planejamento estratégico, para avaliar as possibilidades de convivência dos dois segmentos, numa situação de expansão e consequentemente, não cogitou estabelecer parcerias entre os setores público e privado (NASCIMENTO; CABRAL NETO, 2011).

Provavelmente essa realidade exigiu uma série de modificações, como na Lei 10.260 de 2001, a qual trata do financiamento estudantil - FIES, excluindo o indivíduo de baixa renda e ainda que modificada posteriormente não o incluiu e no ano de 2004 o governo criou o Programa Universidade para todos - PROUNI, que foi instituído em 2005 pela Lei $\mathrm{n}^{\circ} 11.096$ de 2005, com a contrapartida da isenção de tributos para as IES, tudo de cima para baixo sem qualquer negociação com o segmento privado de ensino (BRASIL, 2005).

A necessidade de integração dos setores no momento da expansão permaneceu como um ponto obscuro e foi possivelmente uma grande motivadora do colapso do setor privado, o qual também foi atingido pela ausência de planejamento estratégico, pois para uma ampliação desse porte que exige um significativo contingente de pessoas em condições de bancar mensalidades escolares é mister que se conheça as características econômicas dos lugares onde um investimento privado em IES possa ser coerente e consistente.

No caso do sulmaranhense, a impressionante dinâmica populacional mostrada no quadro 4 instigou a abertura de faculdades particulares sem um adequado estudo da demanda e oferta, por exemplo: quantas pessoas podem pagar e estão dispostas a estudar em uma Instituição de Ensino Superior 
privada nessa região e qual a quantidade de vagas ofertadas atualmente neste nivel de ensino. Quantos professores habilitados para o ensino superior existem disponiveis. Estas são indagações básicas diante de uma proposta de ampliação desse ensino, para não comprometer a qualidade.

Diferente de outros investimentos empresariais, o ensino superior numa região apresenta uma limitação relacionada com a projeção dessa demanda, ou seja uma pessoa em média conclui um curso superior em 4 anos e para se atingir a idade de ingressar numa faculdade um indivíduo leva em média 17 anos, entretanto observando por essa ótica uma IES apresenta um poder maior de consumo em relação ao tempo em que uma população projeta um consumidor de ensino superior.

Esse constructo analítico demonstra que uma oferta de vagas nesse nivel superior exige sério planejamento em função das limitações impostas por esses fatores dessa realidade escolar, principalmente considerando outras variáveis, como: renda, preferência por determinados cursos inexistentes e desinteresse pelo ensino superior e a tendência da queda na taxa de fecundidade (IBGE, 2008).

Nesse contexto de limitações e expansão desordenada encontram-se exemplos em Imperatriz a partir do quadro 5, e algumas IES que atingiram niveis preocupantes de grande queda de matrículas, optaram para a negociação com grandes conglomerados educacionais que já assumiram a propriedade como foi o caso da Faculdade Atenas Maranhense - FAMA, adquirida pelo grupo Pitágoras e a Faculdade de Imperatriz / FACIMP pelo grupo DeVry.

Para Saviani (2010), com essa expansão aprofunda-se a tendência da educação superior ser tratada como mercadoria e entregue aos cuidados de empresas de ensino, pois como se trata de uma estruturação guiada por uma mantenedora provendo uma IES e em grande parte essa mantenedora sobrevive da instituição de ensino, fatalmente o caráter mercantil ficou explícito e por essa ótica o direcionamento da educação para o mercado de trabalho a partir da Teoria do Capital Humano, se identifica com essa gestão 
de cunho econômico e sua regulação e publicidade é conduzida através dos números.

Para Morin (1996), a ciência tornou-se uma poderosa e consistente instituição no centro da sociedade, protegida e controlada pelos poderes econômicos e politicos. Assim, a tecnologia produzida pelas ciências transforma a sociedade, mas também, retroativamente, a sociedade avançada transforma a própria ciência. A ciência é construída através de um processo da participação de diversos agentes, sendo influenciada por estes, mas também exerce sua influência, limitada ao poder do estado e do grande capital.

Esse crescimento, que transmite a falsa ideia de desenvolvimento regional, não contribui para a melhoria da qualidade de vida da população em termos igualitários, o fato é que, a educação no contexto do desenvolvimento e sob as bases da Teoria do Capital Humano mantem o tradicionalismo da propriedade dos meios de produção nas mãos das classes dominantes, com uma hierarquia ascendente até alcançar a grande empresa de capital global, como ocorreu com as duas IES exemplificadas, estabelecendo uma concentração de renda que se perpetua em todo o país.

Na concepção de Frigotto (2010), alcançar o desenvolvimento através da educação no Brasil é uma incógnita, pois a história muda, mas o caráter de formação desigual continua com o mesmo germe indutor de um domínio restrito, essa visão é compartilhada com Florestan Fernandes, Antônio Cândido e Saviani (2010), que consideram a necessidade de mudanças na estrutura educacional brasileira e contestam a permanência de um dualismo presente e inexorável no contexto social brasileiro, superando as mudanças econômicas e políticas ao longo da trajetória histórica.

Para eles, as mudanças ocorridas na educação no século atual não coincidem com os anseios e as expectativas da sociedade para eliminação de focos da dependência que reduzem a liberdade intelectual, em virtude dos modelos importados e orientados por um conjunto de estilos globais.

A expansão do ensino superior obedeceu prioritariamente ao ato de inflar, dilatar e expandir, criando uma procura desordenada por cursos superiores, uma busca de um título fácil, como se fosse uma chave mestra que 
abre o mercado de trabalho independente da qualidade. Essa explosão quantitativa de instituições e cursos deu origem a um mercado paralelo, não institucionalizado, com preços para compra de IES em declínio com a utilização de um parâmetro - quantidade de aluno, tendo esse como unidade de medida mercadológica que varia de preço em função de algumas variáveis mercadológica presentes na instituição.

O estado com seu poder regulador, mas orientado por uma força maior da globalização permitiu que a estrutura expansionista do ensino superior produzisse inicialmente uma grande quantidade de matrículas, entretanto não foi possivel produzir na mesma magnitude um elenco de docentes capacitados para essa missão. A crise na qualidade do ensino era inevitável e essa irradiouse pelas IES particulares até quando o Ministério da Educação, tardiamente, em 2004 instituiu o Sistema Nacional de Avaliação da Educação Superior SINAES, iniciando assim um processo de busca da qualidade ou uma forma de minimizar prejuízos.

A estruturação da hipótese iniciada nesse parágrafo anterior permite entender que, provavelmente não houve falta de planejamento público ocasionando assim uma crise, mas, um plano estratégico orientado para estabelecer um limite num dado momento e esse como não foi previsto anteriormente pelos investidores surpreendeu os gestores das IES privadas, ocasionando fechamento de cursos por falta de qualidade e/ou excesso de oferta para uma limitada demanda em termos de renda (ver quadro 5).

Admitindo-se essa hipótese aproxima-se também da lógica de estruturação dos mercados quando no seu início existe uma gama de facilidades para entrada e no médio prazo grande parte dos pequenos, médios e grandes investidores são dominados pelos grandes grupos econômicos (multinacionais).

Observando como Marx e Engels (2006) analisam a formação da sociedade entende-se que a história não é um processo linear e contínuo, pelo contrário, é caracterizada pelas transformações sociais determinadas pelas contradições entre os meios de produção e as forças produtivas, pois os 
detentores do poder econômico influenciam a construção das normas e a criação dos instrumentos de controle.

Diante dessa concepção de formação da sociedade questiona-se, porque expansão do ensino superior e para quê? Tradicionalmente uma sociedade movimenta-se produtivamente com um número significativamente maior de mão de obra de nível técnico do que de profissionais de nivel superior, para essa confirmação basta observar, a organização da produção de uma sociedade através dos setores: construção civil, as montadoras de veículos, autopeças, os setores de produção de alimentos, as montadoras de produtos eletroeletrônicos, fábricas de brinquedos, os profissionais técnicos em enfermagem numa unidade de saúde, entre outros que formam um breve conjunto com exemplos que devem ser discutidos e que no momento boa parte das discussões, ungidas pela febre da expansão da educação superior, tangenciam o problema do ensino insuficiente no Brasil.

No ponto de vista de Pastore (2000), a "educação sozinha não gera emprego", nesse entendimento ele procura rechaçar os adeptos da aquisição do título de nivel superior a qualquer custo, como um cartão de ingresso e permanência no mercado de trabalho. Esses dois últimos parágrafos pretendem abrir uma provocação para um melhor entendimento de uma educação continuada e adequada às pessoas que formam a força de trabalho numa determinada sociedade.

A frequente qualificação educacional relacionada à formação de cada uma das pessoas, independentemente do nivel técnico ou superior, pode garantir a empregabilidade, entretanto, no Brasil, a força de trabalho tem em média 5 anos de escola e de má qualidade, que é insuficiente para se acompanhar as mudanças meteóricas que ocorrem no mundo tecnológico. A força de trabalho da Coréia do Sul tem 10 anos de boa escola, a do Japão tem 11; a dos Estados Unidos 12; e a maior parte dos países da Europa tem mais do que isso. Por esses demonstrativos talvez fosse melhor expandir ensino fundamental e médio (PASTORE, 2013).

Essas premissas apoiam-se em fatos da realidade brasileira, que exibem como exemplo um resultado de sua estrutura educacional com $13,3 \%$ de 
analfabetos no universo das pessoas de 15 anos ou mais da população e no contexto espacial deste artigo, o Nordeste, essa realidade é bem mais crítica representada por $26,6 \%$ nesse mesmo universo (IBGE, 1999).

Nesse caso é pouco provável que a decisão de ampliar vagas para o ensino superior tenha sido tomada desconhecendo essas estatísticas e que a crença no espectro da educação para o desenvolvimento tenha apontado o ensino superior como a primeira prioridade ao ponto de prescindir do fortalecimento do ensino fundamental e médio como base precípua de um desenvolvimento regional.

\section{Considerações Finais}

O presente estudo analisou a expansão do ensino superior privado no Brasil e sua influência no desenvolvimento regional, e no elenco de discussões atinentes à ampliação desse ensino creditou-se ao estado por essa iniciativa a partir dos seus instrumentos legais. A Lei de Diretrizes e Bases da Educação subsequente à Constituição Federal de 1988 integra o efeito expansionista e ao mesmo tempo em que induz a iniciativa privada a adentrar num sensível segmento cuja atribuição e condução deveria ser exclusiva dos governos através das instituições, ou seja, universidades públicas de boa qualidade.

Nas inserções discursivas e esclarecedoras da relação educação superior e desenvolvimento valorizou-se pontos de vista de Frigotto (1999; 2000) quanto ao papel da educação, que sofre interferência da estrutura econômica e social dominante, através de um pseudo horizonte de melhorias globalizantes, enquanto Veiga (2005) orientou explicações no sentido de atenuar as mistificações sobre a igualdade crescimento/desenvolvimento, que por conseguinte, neste artigo, favoreceu a direção alinhada à concepção de construção da ciência pelos distintos agentes na qual o domínio na maioria das vezes pertence ao estado e o grande capital.

Desse modo, credita-se aos citados agentes a capacidade de edificar sua própria história, como no exemplo dos dados coletados acerca da expansão do ensino superior, no estado do Maranhão e no município de Imperatriz, onde resultados provenientes de investimentos privados nesse ensino aproximaram- 
se de uma via desenvolvimentista, de cunho econômico, transformando grande parcela das Instituições de Ensino Superior privado em indutoras de parte de um emergente mercado da educação.

Uma expansão para criação de mercados, que produziu de forma rápida dados estatísticos de crescimento expressivos, principalmente no Nordeste do paîs, podendo inclusive servir ao marketing internacional da educação, mas não foi capaz de mudar nessa mesma magnitude a qualificação no ranking mundial. O grande envolvimento com a expansão do ensino superior parece ter deixado o ensino fundamental e médio em estado de letargia, que somente agora busca-se compensar o distanciamento entre a base e a educação superior, bem como aproximar parâmetros curriculares com demais países emergentes.

\section{Referências}

AMRIEI. Rodnlfo A. M. Construıcão da escala de motivos nara evasãn do ensino sunerior. Aualiacão Psicolóaica. Itatiha. v. 14. n. 1. ahr. 2015. Disnonivel em: <httn: / / nensic. hvsalid .org/scieln. nhn?scrint=sci_arttext\&pid=S167704712015000100006>. Acesso em: 5 nov. 2016.

ANDRADE, Dorlice Souza. Universidade e ensino superior em Imperatriz. 2006. Dissertação (Mestrado em Planejamento do Desenvolvimento) - Universidade Federal do Pará, Belém, 2006.

BRASIL. Lei $n^{\circ} 11.096$, de 13 de janeiro de 2005. Institui o Programa Universidade para Todos - PROUNI, regula a atuação de entidades beneficentes de assistência social no ensino superior; altera a Lei no 10.891, de 9 de julho de 2004, e dá outras providências. Disponivel em:

<http://www.planalto.gov.br/ccivil_03/_ato2004-2006/2005/lei/11 1096.htm>. Acesso em: 28 jun. 2016.

BRASIL. Lei $n^{\circ}$ 9.394, de 20 de dezembro de 1996. Estabelece as diretrizes e bases da educação nacional. Disponivel em:

<http://www.planalto.gov.br/ccivil_03/leis/L9394.htm>. Acesso em: 2 jul. 2014.

CHAVES, Vinicius. Educação superior e desenvolvimento: o papel das instituições de ensino superior privadas na concretização dos objetivos fundamentais da Reníhtica ? 14 . Disnonílel e.m.

Figueiredo<www. nublicadireito.com.br/artigos /?cod=0428be7495f8f382>.

Acesso em: 11 jul. 2016.

CUNHA, Luiz Antônio. O desenvolvimento meandroso da educação brasileira entre o estado e o mercado. Educação e Sociedade, Campinas, v. 28, n. 100, p. 809-82.9. nut. 2007. Disnonivel em: <www.scielo.br/pdf/es/v28n100/a0928100.pdf>. Acesso em: 25 mar. 2017.

DEMO, Pedro. Educação e desenvolvimento: mito e realidade de uma relação possivel e fantasiosa. Campinas: Papirus, $1 \overline{9} 99$. 
Santos, E.O.; Loiola, E.; Santos, S.O

ENCICLOPÉDIA DE IMPERATRIZ. Imperatriz. Instituto Imperatriz, 2003.

ETENE. Consumo de produtos industriais na cidade de Imperatriz. Fortaleza: Etene, 2002.

FAUSTO, Boris. História do Brasil. São Paulo: EDUSP, 1995.

FERRO, Wilson Pires. Espelhos de São Luis: artigos e crônicas. São Luís: Lithograf, 2005.

FLECK, M. P. A. et al. Aplicação da versão em português do instrumento abreviado de avaliação da qualidade de vida "WHOQOL-Brief". Revista de Saúde Pública, v. 24, n. 2, p. 178-183, 2000.

FRIGOTTO, Gaudêncio. A produtividade da escola improdutiva. São Paulo: Cortez, 1999.

FRIGOTTO, Gaudêncio. Educação e crise do capitalismo real. São Paulo: Cortez, 2000.

FRIGOTTO, Gaudêncio. Os circuitos da história e o balanço da educação no Brasil na primeira década do século XXI. Revista Brasileira de Educação, Rio de Janeiro, v. 16, n. 46, jan./abr. 2010. Disponível em:

<http://www.scielo.br/pdf/rbedu/v16n46/v16n46a13.pdf $\geq$. Acesso em: 8 ago. 2015 .

FURTADO, Celso. Introdução ao desenvolvimento: enfoque histórico-estrutural. 3. ed. São Paulo: Paz e Terra, 2008.

IRGE. Pesauisa nacional nor amostra de domicílins. 1999. Disnonivel em <httns: / / hiblinteca ihoe. gnv.hr/visualizacao/periodicos/59/pnad_1999_v21_br .pdf>. Acesso em: 2 abr., 2017.

IBGE. Pesquisa nacional por amostra de domicílios: sintese de indicadores 2008. Disponivel em:

<https://ww2.ibge.gov.br/home/estatistica/populacao/trabalhoerendimento/ pnad2008/default.shtm>. Acesso em: 6 fev. 2017.

INEP. Censo da educação superior 2010: divulgação dos principais resultados do censo da educação superior 2010. Brasília, 2011. Disponivel em:

$<$ http://download.inep.gov.br/educacao_superior/censo_superior/documentos /2010/divulgacao_censo_2010.pdf>.Acesso em: 12 mar. 2017.

INEP. Resumo técnico: censo da educação superior 2008: (dados preliminares). Brasília, 2009. Disponivel em:

<http://download.inep.gov.br/download/censo/2008/resumo_tecnico_2008_1 5_12_09.pdf >. Acesso em: 2 jul. 2014.

INEP. Resumo técnico: censo da educação superior de 2009.Brasília, 2010. Disponivel em:

<http://download.inep.gov.br/download/superior/censo/2009/resumo_tecnic o_2009.pdf>. Acesso em: 9 jul. 2015.

MARX, Karl; ENGELS, Friedrich. Obras escolhidas. São Paulo: Alfa-Omega, 2006. v. 1.

MOEHLECKE, Sabrina; CATANI, A. M. Reforma e expansão do acesso ao ensino superior: balanço e proposições. Brasília: INEP, 2006. (Série Documental).

MORIN, Edgar. Ciência com consciência. Rio de Janeiro: Bertrand Brasil, 1996. 
NASCIMENTO, Ilma Vieira; CABRAL NETO, Antônio. A expansão da educação superior no Maranhão: cenário atual e tendência. São Paulo: Xamã, 2011.

NEGREIROS, Sebastião. A história de um jornalista despretensioso, fatos que marcaram a história de Imperatriz. Imperatriz: Ética, 1996.

PASTORE. . Insé. Fducação para o trabalho. Correio Braziliense, Brasília, 3 jun. 2013. Disnonivel em:

<httn: //www.josepastore.com.br/artigos/ed/ed_055.htm>. Acesso em: 24 abr. 2017.

PASTORF. . Insé. Trahalho sem emprego. Cadernos de Administração do SENAC, Rio de Janeiro, 2000. Disponivel em:

<http://www.josepastore.com.br/artigos/em/em_043.htm>. Acesso em: 24 abr. 2017.

SAMPAIO, H. Ensino superior no Brasil: o setor privado. São Paulo:

Fapesp/Hucitec, 2000.

SANTOS, Edgar Oliveira. Característica e perspectivas de Imperatriz como cidade-pólo do Sul do Maranhão. Revista Econômica do Nordeste, Fortaleza, v. 39, n. 3, 2008.

SAVIANI, Dermeval. A expansão do ensino superior no Brasil: mudanças e continuidades. Revista Poiesis Pedagógica, Catalão, v. 8, n. 2, ago./dez. 2010. Disponivel em:

<http://www.revistas.ufg.br/index.php/poiesis/article/view/14035>. Acesso em: 5 ago. 2015.

SEN, Amartya. Development as freedom. New York: Anchor Books, 1999.

Disponivel em: <http:7/www.c31.uni-oldenburg.de/cde/OMDE625/Sen/Senintro.pdf>. Acesso em: 30 jan. 2017.

SGUISSARDI, V. Reforma universitária no Brasil - 1995-2006: precária trajetória e incerto futuro. Educação \& Sociedade, Campinas, v. 27, n. 96, p. 1021-1056, out. 2006.

VEIGA, José Eli da. Desenvolvimento sustentável: o desafio do século XXI. Rio de Janeiro: Gramond, 2005. 